\title{
Iconografía comparada en las ediciones de Amadís de Grecia/Amadis de Grèce de Feliciano da Silva
}

Recibido: 31/07/2015

Aceptado: 13/11/2015

\section{RESUMEN:}

En el marco de este artículo comparamos los grabados de Amadís de Grecia de Feliciano da Silva y su traducción francesa, los libros VII et VIII del ciclo de Amadis. Confirmamos la tesis emitida acerca de los libros anteriores, especialmente los de Garci Rodríguez de Montalvo, dando fe de una difusión francesa que se adaptó al gusto del lector de aquel país. Nuestro análisis se centra en el horizonte de expectativas sugerido por el uso de la iconografía en ediciones destacadas de la obra, en España, París y Flandes. PALABRAS CLAVE: Amadís de Grecia, Feliciano da Silva, Nicolas Herberay des Essarts, iconografía comparada, libros VII y VIII de Amadis

\section{ABSTRACT:}

In the frame of this article, we compare the engravings of Feliciano da Silva's Amadís de Grecia and its French translation, the books VII and VIII of the Amadis cycle. We confirm the thesis about the books issued earlier, especially Garci Rodríguez de Montalvo's, attesting French diffusion was adapted to suit the reader from that country. Our analysis focuses on the horizon of expectations suggested by the iconography in outstanding editions of the work, in Spain, Paris and Flanders.

KEY WORDS: Amadís de Grecia, Feliciano da Silva, Nicolas Herberay des Essarts, comparative iconography, books VII and VIII of Amadis 


\section{Introducción}

La iconografía literaria ${ }^{1}$ es un campo en el que mucho queda por estudiar. Dentro del medievalismo se analiza el diálogo de la iluminación con el texto que la acompaña (o al revés), dedicándose a uno o varios testimonios manuscritos (con el fin de comparar los ciclos iconográficos) ${ }^{2}$. Dicho campo también irrumpió en el ámbito de la historia del libro impreso, especialmente en su fase inicial, en el Renacimiento ${ }^{3}$. Por ejemplo, la atención prestada por los filólogos a la reutilización de grabados de una obra a otra por parte de un impresor (que se vale de su propio material o del que cogió prestado de un compañero) nos brinda un mejor conocimiento de las prácticas y técnicas desarrolladas por los artesanos del libro renacentista, lo que forma parte de los elementos significativos que determinan la transmisión de textos ${ }^{4}$.

En el caso de los libros de caballerías, el cuidado en la elección de los grabados parece haber sido mayor que para otros gé-

1 Este trabajo se inserta en el proyecto FFI2012-31813 (Selecciones de discursos de origen historiográfico desde la Antigüedad hasta el Renacimiento II) del grupo de investigación ARENGA. Retórica e Historiografía desde la Antigüedad hasta el Renacimiento de la Universidad de Extremadura.

2 Un ejemplo entre otros, SAlvo García, Irene: «Images de la construction ou la construction imaginée: les miniatures des manuscrits des Cantigas a Santa María d'Alphonse X», in V. Obry \& C. Dauphant (eds.), Rêves de pierre et de bois. Imaginer la construction au Moyen Âge, Paris, PUPS, 2009, págs. 23-32.

3 Para estudios monográficos sobre este campo, véase Lucía Megías, Juan Manuel, Imprenta y libros de caballerías, Madrid, Ollero \& Ramos, 2000. Asimismo sobre bibliografía material es de destacar el libro de Mercedes Fernández ValLadAres, La imprenta en Burgos (1501-1600), Madrid, Arco Libros, 2005.

4 Evidenciamos que la xilografía utilizada por Pierre le Caron en la portada de su incunable del Triumphe des dames (traducción francesa del Triunfo de las donas de Juan Rodríguez del Padrón) fue cogida prestada de Antoine Vérard y que fue utilizada en varias obras, SERrano, Florence, La Querelle des femmes à la cour, entre la Castille et la Bourgogne, au XV siècle: étude et édition critique du Triunfo de las donas/Triumphe des dames de Juan Rodríguez del Padrón, tesis doctoral dirigida por C. Heusch y V. Duché, ENS de Lyon, 2011. 
neros literarios. Su reutilización ${ }^{5}$ se debía generalmente a que el artesano de una nueva edición asociaba el lectorado que ideaba para esta con el lectorado de una obra para la que había sido utilizado el grabado. En alguna ocasión, el rastreo de los ciclos de grabados en los libros de caballerías fue un elemento determinante para datar ediciones (en el caso de que no fuesen fechadas o de que la fecha impresa no se correspondiera con la realidad) o alegar la existencia de más ediciones que las que se conservan hoy día 6 . Por tanto, estudiar la iconografía de ediciones antiguas de obras pertenecientes al género caballeresco precisa su recepción, es decir el horizonte de expectativas de los lectores así como el imaginario convocado ${ }^{7}$.

Para entender mejor la pujanza del ciclo del Amadís de Gaula en la cultura europea renacentista fueron estudiados tapices ${ }^{8}$,

5 Alvar, Carlos: «De La Celestina a Amadís: el itinerario de un grabado», in: Filologia dei testi a stampa (area iberica), (ed.) P. Botta, Modena, Mucchi Editore, 2005, págs. 97-110; СACHо BlECUA, Juan Manuel: «Los grabados del texto de las primeras ediciones del Amadís de Gaula: del Tristán de Leonís (Jacobo Cromberger, H. 15031507) a La Coronación de Juan de Mena (Jacobo Cromberger, 1512)», Rilce, 23, 1, 2007a, págs. 61-88; id., «Iconografía amadisiana: las imágenes de Jorge Coci», eHumanista. Journal of Iberian Studies, 16, 2010b, págs. 1-27.

6 Id., «La configuración iconográfica de la literatura caballeresca: el Tristán de Leonís y el Oliveros de Castilla (Sevilla, Jacobo Cromberger)», Letras. Libros de caballerías. El «Quijote». Investigación y Relaciones, 50-51, 2004-2005, págs. 51-80.

7 Para una inclusión de elementos caballerescos en la historiografía mediante el uso de la iconografía, véase $i d$., «Texto, grabado y configuración genérica de la Crónica popular del Cid», in: El Cid: de la materia épica a las crónicas caballerescas. Actas del Congreso Internacional «IX centenario de la muerte del Cid», celebrado en la universidad de Alcalá de Henares, (eds.) C. Alvar, F. Gómez Redondo \& G. Martin, Alcalá de Henares, Universidad, 2002, págs. 339-359.

8 Pinet, Simone: «Los tapices de la Historia de Amadís de Gaula», in: Amadís de Gaula, 1508: quinientos años de libros de caballerías, (ed.) J. M. Lucía Megías, Madrid, Biblioteca Nacional de España - Sociedad Estatal de Conmemoraciones Culturales, 2008, págs. 403-405. 
cerámicas $^{9} \mathrm{o}$ incluso la documentación de una boda en la alta nobleza francesa ${ }^{10}$. Una proposición inversa, estudiar huellas de una iconografía preexistente en el texto, también fue emprendida en el ámbito de la heráldica amadisiana ${ }^{11}$. Esto plantea el problema del estatuto de la descripción y de su posible duplicidad debida a la coexistencia de ilustraciones y de fragmentos descriptivos del texto. En efecto, las posibles ekfrasis o escenas visuales pueden originarse en el texto y verse representadas en los grabados (pues estos por definición tienen como función el dar a ver). ¿La descripción textual es forzosamente más importante que los elementos iconográficos en el ciclo amadisiano? De hecho, el vínculo entre grabado y texto suele ser menos estrecho que entre iluminación y texto manuscrito, debido justamente a la frecuente reutilización xilográfica: con todo, a medida que van pasando los años de difusión de una misma obra, aumenta globalmente el grado de simbiosis imagen-texto. Existe otra vía fructífera para el estudio de la recepción de la novela caballeresca, que es el análisis comparativo de la iconografía en las ediciones de una misma obra a escala europea, lo que José Manuel Lucía Megías sugirió

9 CACHO BleCUA, Juan Manuel: «Iconografía amadisiana: las cerámicas esmaltadas italianas de ¿Orazio Fontana? h. 1560-1570», in: Il mondo cavalleresco tra immagine e texto (Trento, Castello del Buon Consiglio, 20-22 novembre 2008), (ed.) C. Demattè, Trento, Università degli Studi di Trento, 2010a, págs. 45-84.

10 Vargas Díaz-Toledo, Aurelio: «Huellas del Amadís en Francia (las fiestas celebradas en Châtellerault, en 1541, con motivo de la boda de Jeanne d'Albret y Guillaume de la Marck)», in: Amadís de Gaula: quinientos años después. Estudios en homenaje a Juan Manuel Cacho Blecua, (eds.) J.M. Lucía Megías, Mª.C. Marín Pina, con la colaboración de A.C. Bueno, Alcalá de Henares, Centro de Estudios Cervantinos, 2008, págs. 819-834.

11 Sales Dasí, Emilio José: «Una primera aproximación a la heráldica literaria de las continuaciones caballerescas del Amadís de Gaula», Emblemata. Revista Aragonesa de Emblemática, IX, 2003, págs. 219-230. Sin embargo, el estudioso llega a la conclusión que, en el caso de la heráldica, esta vía sería un espejismo, en tanto que la ficción no quiere ser un fiel reflejo de la realidad del mundo. 
al estudiar la labor de los Cromberger ${ }^{12}$, labor que fue analizada magistralmente por Clive Griffin ${ }^{13}$. Si bien las vías abiertas abundan y son amplias, cabe restringir nuestro enfoque.

En el marco del presente artículo, nos dedicamos a analizar la iconografía de las ediciones del Amadís de Grecia y del Amadis de Grèce, su traducción al francés (se trata de un primer paso antes del cotejo entre texto e imagen en dicha obra). Esta obra fue poco estudiada en comparación con los primeros libros del ciclo, aunque más que los libros de la tradición heterodoxa del Amadís. La segunda parte se conoce en la tradición textual francesa como el octavo libro de Amadis $^{14}$ y en la tradición original como la segunda parte del libro noveno ${ }^{15}$; la primera parte constituye el libro séptimo en la tradición francesa. Ya fueron apuntadas algunas diferencias entre la iconografía amadisiana de las ediciones en el texto original y de las ediciones en francés:

$\mathrm{Al}$ igual que ya hiciera Montalvo con los manuscritos del Amadís medieval, que los adaptó a la corriente ideológica de la corte de los Reyes Católicos, Herberay también realizó las pertinentes modi-

12 Lucía Megías, Juan Manuel: «Las xilografías caballerescas de la Crónica del santo rey don Fernando tercero (Sevilla, Jacobo Cromberger, 1516)», in: J. M. Lucía Megías y Mạ .C. Marín Pina (eds.), con la colaboración de A. C. Bueno, Amadís de Gaula: quinientos años después. Estudios en homenaje a Juan Manuel Cacho Blecua, Alcalá de Henares, Centro de Estudios Cervantinos, 2008a, págs. 413-456.

13 Griffin, C., The Crombergers of Seville: The History of a Printing and Merchant Dinasty, Oxford, Clarendon Press, 1988. Cabe precisar que la edición de la traducción española carece de las dos mil microfichas (Grifrin, C., Los Cromberger. La historia de una imprenta del siglo XVI en Sevilla y Méjico, Madrid, Ediciones de Cultura Hispánica, 1991).

14 Colaboro en la edición crítica de la segunda parte del Amadis de Grèce a cargo de Véronique Duché. Esta labor forma parte del proyecto de edición que se materializa con la colección dirigida V. Duché «Romans de chevalerie de la Renaissance» de la editorial parisina Classiques Garnier.

15 La edición crítica de la primera parte del Amadís de Grecia está también en preparación, a cargo de Eglal Henein. 
ficaciones para que dicha obra fuera acogida por parte de su nuevo público como algo original, adecuando el texto al espíritu de la nobleza y de la aristocracia francesas. Con vistas a lograr este objetivo se llevaron a cabo un conjunto de cambios que afectaron tanto a sus características externas como a su configuración interna: en cuanto a las primeras, la página se dispuso a línea tirada, los caracteres góticos fueron sustituidos por los romanos y las ilustraciones a página completa se transformaron en unas más pequeñas situadas al inicio de cada capítulo y alusivas al contenido del mismo; en relación a la segunda, el Amadís pasó a convertirse en un auténtico manual de «cortesanía» (Place, 1954) ${ }^{16}$.

Nuestro objetivo es averiguar si la misma tendencia caracteriza concretamente el Amadís de Grecia de Feliciano da Silva, es decir el noveno libro (en el ciclo amadisiano original) y los libros séptimo y octavo de la traducción francesa. Después de Montalvo, puede que Feliciano da Silva haya sido el autor que más contribuyó al florecimiento del ciclo amadisiano: el propio Silva reivindicó el estatuto de continuador del ciclo ortodoxo ${ }^{17}$. Además, existe una continuidad desde las traducciones al francés de los libros de Montalvo hasta las del Amadís de Silva, puesto que todas se deben a Nicolas Herberay des Essarts, quien tradujo los libros primero a octavo del ciclo, entre 1540 y 1548. El Amadís de Silva constituye, pues, la última labor de traducción de Herberay a favor de la difusión del Amadís en Francia. El material iconográfico ya fue reproducido en su mayor parte, por lo que remitimos a su publicación en fuentes modernas o asequibles en la red siempre que es posible. Primero estudiamos los grabados utilizados para las portadas de las ediciones del texto original; a continuación, nos dedicamos al conjunto iconográfico utilizado

16 Vargas Díaz-Toledo, A., «Huellas del Amadís», pág. 828.

17 «Busc[ó] no solo rivalizar con Montalvo y sus continuaciones descubriéndose como el único heredero de la serie, sino convertirse 'en el verdadero y riguroso editor de la casa de Gaula'», Sáinz de la Maza Vicioso, Carlos: «Sinrazón de Montalvo/razón de Feliciano da Silva ('Amadís de Grecia')», Dicenda, 10, 1991, págs. 277-291, pág. 287. 
en las ediciones francesas (de París y de Amberes) y a la reutilización de los grabados.

\section{La iconografía del Amadís de Grecia de Feliciano da Silva}

La edición princeps de El nono libro de Amadís de Gaula, que es la corónica del muy valiente y esforçado príncipe y cavallero de la ardiente espada Amadís de Grecia, hijo de Lisuarte de Grecia, emperador de Costantinopla y de Trapisonda y rey de Rodas, para citar su título completo, fue impresa por Cristobal Francés en Cuenca el 8 de enero de 1530. La segunda sería la de 1535 en Burgos, a cargo de Juan de Junta. Esta edición no difiere de la primera y ambas presentan la misma iconografía.

Después, la obra conoció ediciones en España (y hasta en Portugal, país que contribuyó en gran medida a la difusión del género) a lo largo del siglo XVI. Las ediciones llevan únicamente un grabado en la portada de la obra, es decir, la primera página de la obra de Silva, después del paratexto (Cuenca, 1530, Cristobal francés; Burgos, 1535, "en casa del señor Juan de Junta a costa de Juan de Espinosa"; Jacobo Cromberger, Sevilla, 1542 y 154918; Lisboa, 1596, Simón López ${ }^{19}$ ).

Para el grabado que sirvió para ilustrar las dos primeras ediciones mencionadas (FIG. 1), cabe señalar que fue reproducido como cubierta de la edición de la obra ${ }^{20}$.

18 Estas tres últimas ediciones pueden consultarse desde el portal de la Biblioteca Virtual Cervantes bajo la entrada "Feliciano da Silva": http://www.cervantesvirtual.com/

19 Sin embargo un ejemplar de la misma, conservado en la Biblioteca Universitaria de Madrid (que perteneció a la condesa de Campo-Alange y que está digitalizado en Google Books) no contiene el grabado. Puede que se trate de otra emisión (¿previa?) de la misma edición o que falten folios.

20 Silva, Feliciano da, Amadís de Grecia, (eds.) A. C. Bueno Serrano \& C. Laspuertas Sarvisé, Alcalá de Henares, Centro de Estudios Cervantinos, 2004. 


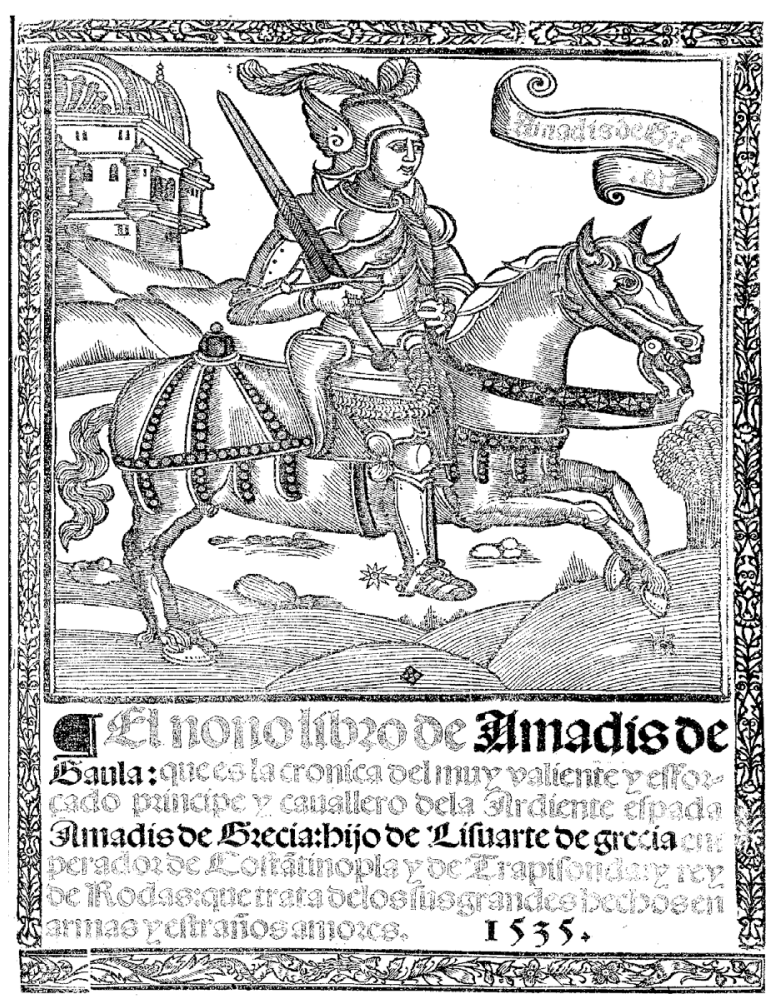

FIG. 1 - Burgos, 1535, Juan de Junta a costa de Juan de Espinosa, infolio ${ }^{21}$

La única diferencia entre el grabado de la edición princeps y el de la siguiente es que esta última fue enmarcada con un friso estrecho. En primer plano se halla el caballero, que identificaríamos difícilmente con el héroe epónimo (ya que la obra también evoca al que funda el ciclo, Amadís de Gaula) si no tuviéramos una filacteria arriba a la derecha que precisa "Amadis de Gre[cia]" en caracteres góticos. Con la mano izquierda sujeta las

21 Reproducción de la portada digitalizada en la Biblioteca Digital Hispánica. Ejemplar de la Biblioteca Nacional de España, signatura U/8571(2). Autorización de publicación para uso público y editorial concedida. 
riendas, con la derecha, su espada alzada. El caballo lleva un rico equipamiento. El caballero, más que nunca andante, mira a lo lejos mientras cabalga, con un aire noble fomentado por su penacho, su armadura y su cara seria. En el segundo plano, aparece un castillo del que el caballero se aleja; abajo un bosque, hacia el que el caballero se dirige. Este grabado simboliza la búsqueda caballeresca tal como se desarrolló desde sus inicios en el marco de la novela artúrica: el caballero tiene que salir de la corte en busca de aventuras, lo que supone el alejamiento de la civilización para adentrarse en la naturaleza más salvaje, indomada y mágica. Este grabado ocupa un poco más de la mitad del folio. Esta portada reproduce la edición de 1525 de Lisuarte de Grecia.

La ilustración siguiente (FIG. 2) sirvió de portada para las dos ediciones sevillanas -a cargo de Jacobo Cromberger, o según lo precisa José Manuel Lucía Megías de sus herederos²2 - es algo más compleja y refleja una pericia mayor del artista: la plantilla que sirvió para el grabado fue entallada de manera más minuciosa y con menos espacio en blanco; con lo cual presentaría menos zonas esculpidas.

22 El grabado está reproducido en las páginas 2 y 3 (no existe una numeración seguida correspondiente al número de la revista), en las ediciones del Amadís de Montalvo, Lucía Megías, Juan Manuel: «Libros de caballerías castellanos en la Biblioteca del Cigarral del Carmen (Toledo)», Tirant, 8, 2005 http://parnaseo.uv.es/ Tirant/Butlleti.8/LibrosCaballeria.pdf 


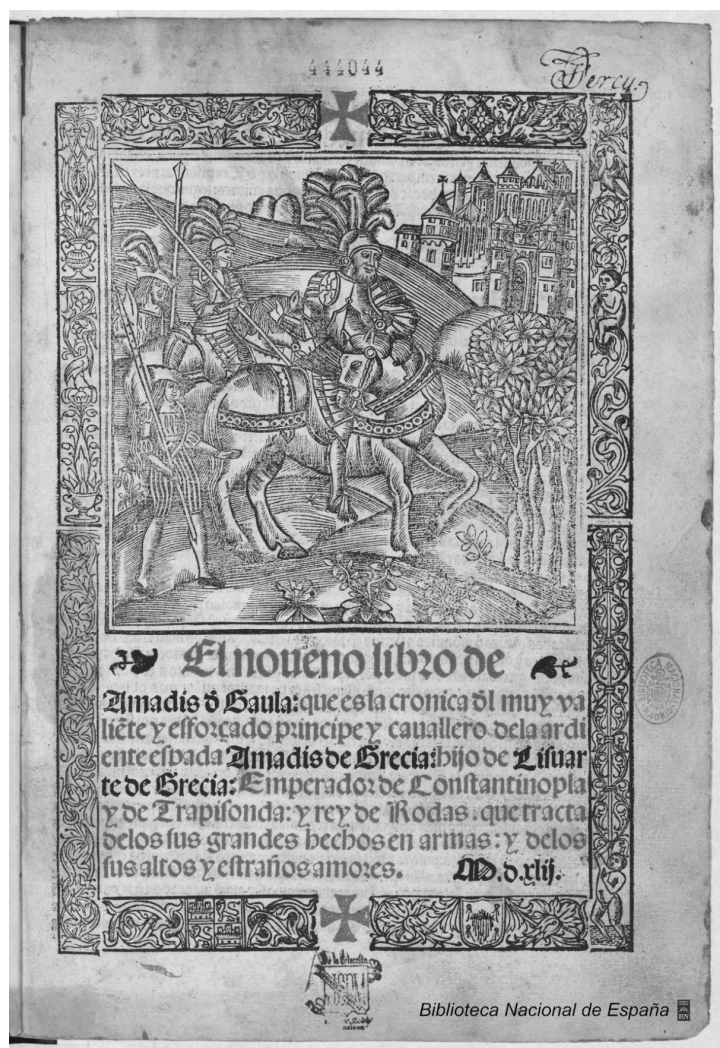

FIG. 2 - Sevilla, 1542, Jacobo Cromberger, infolio ${ }^{23}$

Se trata de una xilografía mucho más elaborada que la precedente, como lo atestigua el hecho de que las partes en relieve del modelo sean muy amplias y los espacios en blanco escasos y repartidos por toda la superficie. Como en muchas otras portadas, caben en la página un grabado -de un tamaño equivalente a sus dos terceras partes- y el título de la obra.

23 Reproducción de la portada digitalizada en la Biblioteca Cervantes Virtual. Ejemplar de la Biblioteca Nacional de España, signatura Cerv. Sedó /8773. Autorización de publicación para uso público y editorial concedida. 
Este grabado se halla también en la edición de 1549 del mismo impresor establecido en Sevilla ${ }^{24}$. Debido a criterios de edición, presentamos una versión en blanco y negro, pero el original presenta las dos cruces (en el recuadro superior e inferior, interrumpiendo el friso) y casi todas las palabras en rojo. Un elemento tipográfico de notar en esta portada es que las palabras en negro destacan más y son palabras claves: "Amadis d[e] Gaula", "Amadis de Grecia" y "Lisuarte de Grecia". La foliación también está impresa en negro. La frisa no solo es geométrica (como la de la edición de Burgos), sino también figurativa: aparecen un ángel, niños, pájaros, ánforas, escudos y grifones.

Los elementos representados en el grabado son los mismos (el caballero andante, el bosque y el castillo), pero están organizados de otro modo con el fin de que quepan otros elementos en el primer plano: los escuderos sujetan una lanza y siguen al héroe y a otro caballero andante (esta desmultiplicación de los personajes simboliza la renovación del ciclo con el paso de una generación a otra y el entrelazamiento de las aventuras caballerescas). Delante de ellos, asoman unos setos, significando la entrada en el bosque. El caballo mira hacia la derecha, lo que aumenta la impresión de que los personajes están en marcha. En el segundo plano, el castillo, por sus numerosas torres, evoca más un palacio digno de la sociedad cortesana que la fortaleza defensiva del grabado anterior. El relieve está dibujado, se distinguen varias colinas detrás de los personajes.

Finalmente, el grabado de la edición lisboeta de 1596 (FIG. 3) recuerda el de las dos primeras ediciones (FIG. 1): su ejecución es sencilla y retoma los mismos elementos que se reparten en las mismas zonas de la imagen. El porte del caballero y las líneas del caballo se asemejan también ${ }^{25}$. tes.

24 Un ejemplar de la edición está digitalizado en la Biblioteca Virtual Cervan-

25 El grabado de esta misma edición se halla también en Lucía Megías, J. M., «Libros de caballerías castellanos», pág. 8. El crítico recuerda que la presunta edi- 


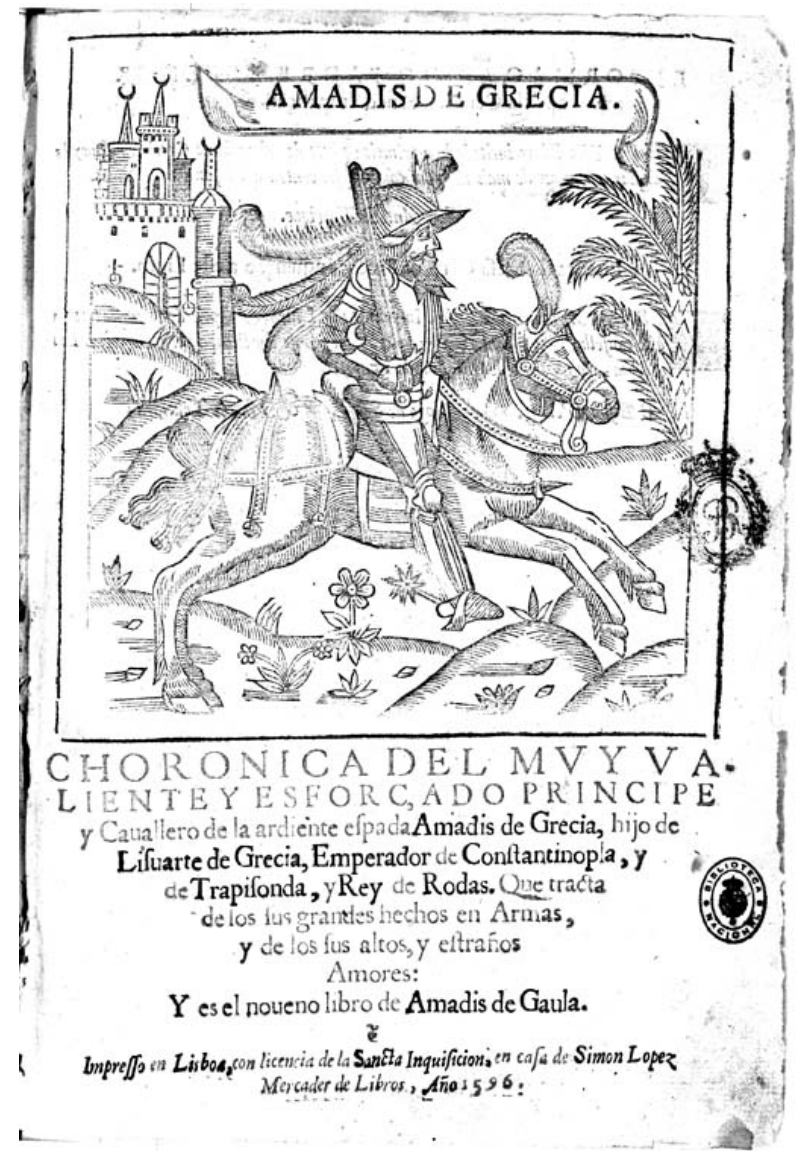

FIG 3 - Lisboa, 1596, Simón López, infolio²6

ción de la obra en Valencia en 1582 es un «fantasma bibliográfico» que nunca existió, ibid., pág. 6.

26 Reproducción de la portada digitalizada en la Biblioteca Cervantes Virtual. Ejemplar de la Biblioteca Nacional de España, signatura R/2525. Autorización de publicación para uso público y editorial concedida. 
Las xilografías siempre representan a un caballero sobre su montura. Tienen en común el representar los mismos elementos que simbolizan la aventura caballeresca, si bien es que el grabado de las dos ediciones sevillanas de Jacobo Cromberger parece más refinado que los otros dos. La ausencia de ilustración intercalada en la obra, característica de las ediciones españolas, se debe al formato de las ediciones, a su tipografía a dos columnas y a las prácticas de los impresores. La ilustración del Amadís de Grecia se caracteriza por su poca complejidad y por la recuperación por parte de los impresores de grabados preexistentes, usados bien para otros libros del ciclo amadisiano, bien para otros libros de caballerías hispanos.

\section{La iconografía del Amadis de Grèce en Francia.}

En 1540, una década después de la primera edición del texto original, ve la luz la primera edición de la traducción de Herberay des Essarts del primer libro del Amadís de Garci Rodríguez de Montalvo. El traductor seguiría, incansable, cumpliendo con su labor de difusión del ciclo en lengua francesa, de tal modo que cada año un nuevo libro traducido pudiese llegar hasta las manos del ávido lector de libros de caballerías: en 1541 está disponible el segundo libro, en 1542 el tercero, en 1543 el cuarto, en 1544 el quinto, el libro sexto (que se corresponde con el séptimo del ciclo original) en 1545, el libro séptimo (que es la primera parte del noveno libro ya mencionado, el de Feliciano da Silva, de ahora en adelante VII) en 1546. El libro octavo (es decir, la segunda parte de la misma obra de Feliciano da Silva, de ahora en adelante VIII) es la última contribución de Nicolas Herberay des Essarts en pro de la traducción del ciclo amadisiano: su primera edición está fechada de 1548. Utilizamos las dos ediciones princeps: para el libro VII, la de 1546 de Jeanne Marnef para Vincent Sertenas (infolio) ${ }^{27}$;

27 http://catalogue.bnf.fr/ark:/12148/cb36127716s 
para el libro VIII, la de Estienne Groulleau de 1548 (infolio), ambas parisinas ${ }^{28}$.

Los libros franceses del ciclo amadisiano están abundantemente ilustrados a diferencia de los españoles, especialmente en el caso de los del Amadis de Grèce. Existen ediciones impresas en París (las primeras y las más numerosas), en Lyon (que aparecieron veinte años después y que no contienen grabados por lo que no las evocaremos) ${ }^{29}$ y las que salieron de las prensas de Amberes (que trataremos en el siguiente apartado).

La labor de Hugues Vaganay ${ }^{30}$ fue determinante para localizar y clasificar las ediciones francesas de los Amadis. Michel Bideaux presentó un estudio del material iconográfico del libro I de Amadis de Gaule ${ }^{31}$. Hace unos años, Jean-Marc Chatelain propuso un análisis de la iconografía de los cinco primeros libros: nos fundamentamos en dicha metodología ${ }^{32}$.

\begin{tabular}{|l|l|l|l|l|}
\cline { 2 - 5 } \multicolumn{1}{c|}{} & $\begin{array}{l}\text { Número de } \\
\text { capítulos }\end{array}$ & $\begin{array}{l}\text { Número de } \\
\text { grabados }\end{array}$ & $\begin{array}{l}\text { Número de } \\
\text { grabados } \\
\text { utilizados }\end{array}$ & $\begin{array}{l}\text { Número de } \\
\text { repeticiones de } \\
\text { grabados }\end{array}$ \\
\hline Libro VII & 63 & 49 & 23 & 26 \\
\hline Libro VIII & 96 & 57 & 25 & 32 \\
\hline
\end{tabular}

28 http://catalogue.bnf.fr/ark:/12148/cb361277263

29 No obstante, la ciudad fue la cuna de la ilustración del libro grabado, en 1478, tres años antes de que la técnica llegue a París, Chartier, Roger \& Martin, Henri-Jean (dir.), Histoire de l'édition française. Le livre conquérant. Du Moyen Âge au milieu du XVII siècle, Paris, Fayard, 1982, pág. 248-252.

30 Vaganay, Hugues (1906), Amadis en français. Essai de bibliographie et d'iconographie, Florence, Olschki, 1546; id.: «Les éditions in-octavo de l'Amadis en français», Revue hispanique, 75, nº167, págs. 1-53, 1929.

31 Rodríguez de Montalvo, Garci: Amadis de Gaule, Livre I, M. Bideaux (ed.), Paris, Classiques Garnier, 2006, págs. 74-84.

32 Chatelain, 2000: 50 
En el libro VII, casi todos los capítulos disponen de su grabado (concordando con el análisis de Place que usamos como punto de partida), después de la mención del título: 14 capítulos no cuentan con un grabado, sino con una inicial adornada con motivos florales, presentan discursos y escenas poco visuales. El número de grabados reutilizados es considerable. Cabe destacar que hay grabados que se repiten varias veces y otros muchos no se reutilizan. De hecho, el grabado del capítulo 14, que muestra navíos, fue usado otras once veces; el del capítulo 5, que representa una batalla entre caballeros sobre su montura, 4 veces, así como el del capítulo 12, que ilustra el combate de soldados bizantinos. Las xilografías de los capítulos 6 y 26 fueron usadas otras dos veces: la primera representa una entrevista entre caballeros; la segunda también, con caballeros en pie. Finalmente, las xilografías de los capítulos 8 y 33 fueron repetidas una segunda vez respectivamente: la primera presenta una escena palaciega, con parejas que hablan en una habitación; la segunda la popa de una carabela a punto de llegar al puerto de una ciudad. Las repeticiones insisten en que las aventuras de este volumen de la serie son marítimas y bizantinas ${ }^{33}$.

Aunque la edición princeps del libro VIII es de dos años posterior a la del VI, los impresores parisinos utilizaron a menudo los mismos grabados. Cabe apuntar que el número de grabados del libro VIII es proporcionalmente menor que el del anterior: la razón es que este volumen, en lo que atañe a su texto, es aproximadamente un $50 \%$ más extenso que el anterior ( 254 folios de numeración moderna para la edición citada del libro VII y 381 para la del libro VIII), por lo que las iniciales adornadas abundan. Asimismo, 39 capítulos están sin ilustrar (contra 14 en el libro VII como ya señalamos). De los 25 grabados usados en el libro VIII, 15 ya lo fueron en el libro VII y por lo menos 3 en ediciones de libros anteriores exceptuando el VII: la reutilización es,

33 Para el estudio de otro ejemplo de modificación del trasfondo cultural mediante la selección de grabados, véase Sanz Julián, 2010. 
pues, óptima, como si los impresores pensaran que, llegados a este punto del ciclo, la ficción hubiese agotado las posibles situaciones descriptivas...

De hecho, entre los grabados reutilizados están unos que fueron usados para las ediciones de los primeros libros del ciclo (las figuras 3, 4, 5, 6 y 8 del artículo de Jean-Marc Chatelain constan en el libro VII y las figuras 1, 2 y 7 en el libro VIII ${ }^{34}$ ), sacados de los libros I a III. Las demás ediciones parisinas presentan los mismos ciclos iconográficos, lo que no debe sorprender, puesto que las ediciones fueron elaboradas mediante la asociación de tres impresores, Jean Longis, Estienne Groulleau y Vincent Sertenas, que vincularon su actividad para proporcionar ediciones de los libros del ciclo entre 1540 y 1560. Sin embargo, un cambio muestra la relevancia cada vez mayor de la iconografía a partir de $1550^{35}$ : desaparece el friso que decoraba el recuadro y el tamaño del grabado aumenta, equiparándose al ancho de columna.

\section{La iconografía del Amadis de Grèce en Flandes}

En aquella época, Flandes era sin duda el territorio de más mestizaje cultural y lingüístico de Europa: convivían personas que hablaban francés, neerlandés (y flamenco) o alemán, y finalmente castellano. Analizaremos la iconografía en la primera edición dada en Amberes, la de Christophe Plantin en 1561 (tanto en el libro VII como en el VIII, en cuartos), así como la de Guillaume (o Willem) Sylvius de 1573 (también en cuartos), con el fin de comparar el uso iconográfico en estas dos ediciones de Amberes y en relación con las ediciones parisinas. Ambas ediciones presentan un texto a dos columnas, como las ediciones del texto ori-

34 Chatelain, Jean-Marc: «L'Illustration des Amadis dans les éditions françaises du XVI e siècle», in: Les Amadis en France au XVI e siècle, Paris, Rue d'Ulm, 2000, págs. 41-52, págs. 47-49.

35 Consultamos el ejemplar digitalizado en Gallica del libro VIII impreso "pour Vincent Sertenas": http://catalogue.bnf.fr/ark:/12148/cb372551277 
ginal. Plantin fue un seguidor de los artesanos parisinos $\left(1561^{36}\right)$ y fue seguido por Sylvius $\left(1573^{37}\right)$. Este dio ediciones muy parecidas a las suyas en cuanto a la tipografía y a la elección de grabados (dio una primera edición de los dos libros, aunque por el número de ejemplares conservados, cabe destacar que su segunda edición conoció posiblemente más éxito y/o que fue más ampliamente difundida). El ciclo iconográfico de las ediciones de Sylvius es una copia de las de Plantin: vienen los grabados en el mismo orden que en la edición amberina de Plantin.

\begin{tabular}{|l|l|l|l|l|l|}
\cline { 3 - 6 } \multicolumn{1}{c|}{} & $\begin{array}{l}\text { Número de } \\
\text { capítulos }\end{array}$ & $\begin{array}{l}\text { Número de } \\
\text { grabados }\end{array}$ & $\begin{array}{l}\text { Número de } \\
\text { grabados } \\
\text { utilizados }\end{array}$ & $\begin{array}{l}\text { Número de } \\
\text { repeticiones de } \\
\text { grabados }\end{array}$ \\
\hline Plantin, VII & 63 & 13 & 10 & 3 \\
\hline Sylvius, VII & & 13 & 10 & 3 \\
\hline Plantin, VIII & \multirow{2}{*}{96} & 28 & 14 & 14 \\
\hline Sylvius, VIII & & 34 & 12 & 22 \\
\hline
\end{tabular}

El libro VIII en la primera edición dada por Plantin contiene 28 grabados de 259 folios de numeración moderna, es decir, en una proporción menor que en la edición princeps parisina (que contenía 57). Además, la edición dada por el mismo impresor de los libros I y II, el año anterior, solo consta de 5 y 2 grabados respectivamente $^{38}$. En 1561, el impresor saca una edición del libro III (9 grabados), IV (7 grabados), V ("chez Jean Waesberghe", 8 grabados), VI (12 grabados). El libro VII consta de 13 grabados. La gradación es, pues, muy marcada, especialmente entre el libro VII y VIII, puesto que se duplica el número de grabados usados.

36 http://catalogue.bnf.fr/ark:/12148/cb37247599g

37 http://catalogue.bnf.fr/ark:/12148/cb37247587g

38 Vaganay, H., Amadis en français, pág. 16. 
Hay que matizar la importancia del aumento, al considerar que el libro VII es más breve que el siguiente (como lo precisamos en el apartado anterior). Parece ser que los impresores se esforzaron por ampliar el número de folios del libro VII y reducir al máximo el del libro VIII. Este aumento coincide en las ediciones parisinas como en las amberinas, prueba que las segundas se fundamentaron en las primeras, aunque los cambios propuestos por Plantin (la introducción de unos grabados panorámicos) fueron seguidos por Sylvius. Es de notar que los números coinciden entre las dos ediciones amberinas del libro VII y que los grabados seleccionados son los mismos, exceptuando el primero.

Como en las ediciones francesas, este aumento podría deberse al gusto del lector, apasionado por la dimensión pintoresca de la obra, lo que se manifiesta con fuerza en los libros VII y VIII, que reanudan el exotismo de las novelas bizantinas. Sin embargo, la mayor diferencia con las ediciones parisinas es que, al tener menos grabados, cada pieza es casi única para las ediciones del libro VII: se practica menos la reutilización de grabados anteriores (solo constan 3 repeticiones para un total de 13 grabados). No obstante, las ediciones amberinas del libro VIII muestran una reutilización tan frecuente como en las ediciones parisinas.

Una diferencia esencial, desde un punto de vista puramente iconográfico, estriba en que las ilustraciones amberinas, al ser más panorámicas, representan escenas con más protagonistas, más planos y un paisaje variado, que une frecuentemente bajo el mismo grabado el mar, el campo (de batalla) y un castillo a lo lejos. Los editores amberinos consiguieron muchos de los grabados usados en las ediciones parisinas, práctica que era frecuente (mediante préstamos, intercambios o compra): por ejemplo, en el f. 28v del libro VIII de la edición de Plantin se halla el mismo grabado que ilustra el capítulo 1 de la edición princeps del libro I del Amadis $^{39}$.

39 Ese grabado está reproducido en Chatelain, J.-M., «L'Illustration des Amadis», pág. 43. 
Aunque los impresores parisinos y amberinos hayan desempeñado su labor en tiempos próximos, su realización difiere tipográficamente (sobre todo en lo que concierne al paratexto ${ }^{40}$. En cuanto a la ilustración, los editores flamencos calcaron sus prácticas sobre las de los editores parisinos, pero limitando el número y por consiguiente la repetición de los grabados e introduciendo una serie de grabados panorámicos realizados con esmero. Las ediciones parisinas y amberinas responden pues, a dos horizontes de expectativas distintos, dictados por una cultura literaria y prácticas de lectura que coinciden en parte.

\section{Conclusión}

Tras el cuadro trazado, desde 1530 hasta los últimos años del siglo e insistiendo en la época de máxima difusión del ciclo (a mediados del siglo XVI), percibimos las evoluciones desde el principio hasta el final de la revolución del libro, por las etapas renacentistas del libro impreso.

La imagen adquiere funciones simbólicas en los grabados de las portadas del Amadís de Grecia: están volcados hacia la corriente más potente de la novela de caballerías, en la que prevalecen las aventuras caballerescas, independientemente de las particularidades narrativas y respecto a la visión de su autor (y al horizonte de expectativas coetáneo). El Amadís de Grecia fue pensado por Feliciano da Silva como una continuación directa del Amadís de Montalvo. Los numerosísimos grabados de las ediciones francesas no conocen exclusividad: su reutilización masiva es la norma. Sin embargo, las xilografías seleccionadas para los libros VII y VIII hacen hincapié en el ambiente bizantino característico de la obra de Silva.

40 Para algunas posibles relaciones entre Francia y Flandes con una evocación de la literatura hispanófona, proporciona datos interesantes Parent, A., Les Métiers du livre à Paris au XVI e siècle (1535-1560), Genève, Droz, 1974. 
A medida que fue prosperando la fortuna amadisiana (que fue intensa tanto en Francia como en España), aumentó la voluntad de los impresores de adecuar la imagen al texto, creando así una simbiosis que particularizó cada vez más su interpretación. Estos cedían a la filosofía humanista de la variedad que rechazaba lo arquetípico, lo que se adecuaba al gusto del público receptor, los cortesanos de Francia y Flandes.

La función complementaria en relación con el texto se fue atenuando: en la edición de Plantin, los grabados bien habrán podido atraer la atención del lector hasta el punto de constituir un elemento de interpretación más importante que el propio texto. El grabado se transforma en una grata sorpresa para el lector a medida que va pasando las páginas. En cambio, su introducción repetitiva, especialmente en el libro VII en la edición parisina de 1546, ritma el conjunto tipográfico: las únicas sorpresas vienen de la utilización de grabados con un formato distinto. Las ediciones se adaptan sin duda a sus destinatarios, de tal modo que la atención no se desviera de manera exclusiva al texto o a la imagen, logrando proponer un equilibrio anhelado por el lector. La función ornamental prevalece y es básica, aunque no es la única.

A pesar de que nos valimos de varios métodos (comparaciones entre grabados, estadísticas y evolución del uso del grabado de un libro a otro...) con el fin de mostrar la variedad del análisis iconográfico comparativo (dentro de una misma obra, a lo largo de su difusión y también entre varias obras), este trabajo solo constituye un eslabón en el estudio de la iconografía amadisiana. Mediante este recorrido, distinguimos el paso del tiempo, desde los últimos atisbos de la Edad Media hasta la primera Modernidad: las xilografías caballerescas de las ediciones del Amadís de Grecia contrastan con grabados como el 431 (libro VIII, capítulo 59, publicado por Hugues Vaganay ${ }^{41}$ ) del amplio ciclo iconográfico amadisiano francófono. Este traduce la evolución social de

41 Vaganay, H., Amadis en français, pág. 80. La numeración del grabado se debe a Vaganay. 
la nobleza, que tiene como consecuencia arquitectónica, la construcción de nuevos palacios, "les hôtels seigneuriaux", para los cortesanos que se instalan en el centro de París. La moda amadisiana en lengua francesa fue tan fuerte, que había conllevado a sus artesanos a concebir grabados para su sola difusión.

\section{Bibliografía}

Alvar, Carlos. «De La Celestina a Amadís: el itinerario de un grabado», in: Filologia dei testi a stampa (area iberica), (ed.) P. Botta, Modena, Mucchi Editore, 2005, págs. 97-110.

Bueno Serrano, Ana Carmen. «Las innovaciones formales de Feliciano de Silva en el Amadís de Grecia: una coda pastoril», in: Lineas actuales de investigación literaria. Estudios de literatura hispánica, (eds.) V. Arenas, J. Badía, A. Chover et alii, Valencia, Universidad, 2005, págs. 165-175.

Bueno Serrano, Ana Carmen «Una ordalía mágico-amorosa en el Amadís de Grecia de Feliciano de Silva», Voz y Letra, 18, 2, 2007, págs. 3-28.

Cacho Blecua, Juan Manuel: «Texto, grabado y configuración genérica de la Crónica popular del Cid», in El Cid: de la materia épica a las crónicas caballerescas. Actas del Congreso Internacional «IX centenario de la muerte del Cid», celebrado en la universidad de Alcalá de Henares, (eds.) C. Alvar, F. Gómez Redondo \& G. Martin, Alcalá de Henares, Universidad, 2002, págs. 339-359.

Cacho Blecua, Juan Manuel. «La configuración iconográfica de la literatura caballeresca: el Tristán de Leonís y el Oliveros de Castilla (Sevilla, Jacobo Cromberger)», Letras. Libros de caballerías. El "Quijote». Investigación y Relaciones, 50-51, 2004-2005, págs. 51-80.

Cacho Blecua, Juan Manuel. «Los grabados del texto de las primeras ediciones del Amadís de Gaula: del Tristán de Leonís (Jacobo Cromberger, H. 1503-1507) a La Coronación de Juan de Mena (Jacobo Cromberger, 1512)», Rilce, 23, 1, 2007a, págs. 61-88. 
Cacho Blecua, Juan Manuel. «Recepción y bibliografía de la literatura caballeresca. 'Amadís', base de datos de Clarisel <clarisel.unizar.es»», in: De la literatura caballeresca al Quijote (coord.) J. M. Cacho Blecua, (eds.) A. C. Bueno Serrano, P. Esteban Erlés, K. X. Luna Mariscal, Zaragoza, Prensas Universitarias de Zaragoza, 2007b, págs. 115-139.

Cacho Blecua, Juan Manuel. «Iconografía amadisiana: las cerámicas esmaltadas italianas de ¿Orazio Fontana? h. 15601570», in: Il mondo cavalleresco tra immagine e texto (Trento, Castello del Buon Consiglio, 20-22 novembre 2008), (ed.) C. Demattè, Trento, Università degli Studi di Trento, 2010a, págs. 45-84.

Cacho Blecua, Juan Manuel. «Iconografía amadisiana: las imágenes de Jorge Coci», eHumanista. Journal of Iberian Studies, $16,2010 b$, págs. $1-27$.

Carro Carbajal, Eva Belén, Puerto Moro, laura \& Sánchez Pérez, María (eds.). in Libros de caballerías (de «Amadís» al «Quijote»). Poética, lectura, representación e identidad, Salamanca, SEMYR, 2002.

Chartier, Roger \& Martin, Henri-Jean (dir.). Histoire de l'édition française. Le livre conquérant. Du Moyen Âge au milieu du XVII ${ }^{e}$ siècle, Paris, Fayard, 1982.

Chatelain, Jean-Marc. «L'Illustration des Amadis dans les éditions françaises du $\mathrm{XVI}^{\mathrm{e}}$ siècle», in: Les Amadis en France au XVI ${ }^{e}$ siècle, Paris, Rue d’Ulm, 2000, págs. 41-52.

Chevalier, Maurice, Sur le public des romans de chevalerie, Talence, Institut d'Études Ibériques et Ibéro-américaines de l’Université de Bordeaux, 1968.

Fernández Valladares, M. La imprenta en Burgos (1501-1600), Madrid, Arco Libros, 2005.

Griffin, C. The Crombergers of Seville: The History of a Printing and Merchant Dinasty, Oxford, Clarendon Press, 1988.

Grifrin, C. Los Cromberger. La historia de una imprenta del siglo XVI en Sevilla y Méjico, Madrid, Ediciones de Cultura Hispánica, 1991. 
Laspuertas Sarvisé, Carmen, Amadís de Grecia de Feliciano de Silva (Cuenca, Cristóbal Francés, 1530), Alcalá de Henares, Centro de Estudios Cervantinos, $2000 . \quad$ Lucía Megías, Juan Manuel, Imprenta y libros de caballerías, Madrid, Ollero \& Ramos, 2000.

Lucía Megías, Juan Manuel. «Libros de caballerías castellanos en la Biblioteca del Cigarral del Carmen (Toledo)», Tirant, 8, 2005 http://parnaseo.uv.es/Tirant/Butlleti.8/LibrosCaballeria.pdf

Lucía Megías, Juan Manuel. «Las xilografías caballerescas de la Crónica del santo rey don Fernando tercero (Sevilla, Jacobo Cromberger, 1516)», in: J. M. Lucía Megías y Ma.C. Marín Pina (eds.), con la colaboración de A. C. Bueno, Amadís de Gaula: quinientos años después. Estudios en homenaje a Juan Manuel Cacho Blecua, Alcalá de Henares, Centro de Estudios Cervantinos, 2008a, págs. 413-456.

Lucía Megías, Juan Manuel. Amadís de Gaula, 1508: quinientos años de libros de caballerías, Madrid, Biblioteca Nacional de España - Sociedad Estatal de Conmemoraciones Culturales, 2008b.

Lucía Megías, Juan Manuel, Marín Pina, María del Carmen \& Bueno Serrano, Ana Carmen (eds.), Amadís de Gaula: quinientos años después. Estudios en homenaje a Juan Manuel Cacho Blecua, Alcalá de Henares, Centro de Estudios Cervantinos, 2008.

Luteran, Paula. Translation or transformation? Herberay des Essarts" "Amadis de Gaula», D.A.I. Ann Arbor, 54/3, 920 A, DA 9321437, University of Pennsylvania, 1993.

Marín Pina, María del Carmen. «Nuevos datos sobre Francisco Vázquez y Feliciano de Silva, autores de libros de caballerías», Journal of Hispanic Philology, 2, págs. 117-130, 1991.

Moral Cañete, Francisco. Feliciano de Silva y el noveno libro del «Amadís de Gaula», el «Amadís de Grecia» (Cuenca, 1530). Edición, estudio preliminar y notas, tesis de doctorado dirigida por J. Lara Garrido y R. Malpartida Tirado, Universidad de Málaga, 2007. 
Moral Cañete, Francisco. «El Amadís de Grecia de Feliciano de Silva en la producción caballeresca hispana (I)», Analecta Malacitana, XXXII, 1, 2009, págs. 59-83.

Moral Cañete, Francisco. «El Amadís de Grecia de Feliciano de Silva en la producción caballeresca hispana (II)», Analecta Malacitana, XXXII, 2, 2009, págs. 433-461.

Mottola, Anthony Clare. The "Amadis de Gaula» in Spain and France, Fordham U., thesis dact. (Diss. Abst., 23, 1368-1369), 1962-1963.

Neri, Stefano. «Cuadro de la difusión europea del ciclo del Amadís de Gaula (siglos XVI-XVII)», in: Amadís de Gaula: quinientos años después. Estudios en homenaje a Juan Manuel Cacho Blecua, (eds.) J. M. Lucía Megías \& Ma‥C. Marín Pina, con la colaboración de A. C. Bueno, Alcalá de Henares, Centro de Estudios Cervantinos, 2008, págs. 565-591.

Ortiz-Hernán Pupareli, Elami. «El motivo del caballero seductor en Amadís de Gaula y Lisuarte de Grecia, de Feliciano de Silva», in: Amadís y sus libros: 500 años, (eds.) A. González; A. Campos García-Rojas, México, D.F., El Colegio de México, Centro de Estudios Lingüísticos y Literarios, 2009, págs. 181-197.

Parent, Annie. Les Métiers du livre à Paris au XVI siècle (15351560), Genève, Droz, 1974.

Pinet, Simone. «Los tapices de la Historia de Amadís de Gaula», in: Amadís de Gaula, 1508: quinientos años de libros de caballerías, (ed.) J. M. Lucía Megías, Madrid, Biblioteca Nacional de España - Sociedad Estatal de Conmemoraciones Culturales, 2008, págs. 403-405.

Place, Edwin B. (1954): «El Amadís de Montalvo como manual de cortesanía en Francia», Revista de Filología Española, XXXVIII, págs. 151-169.

Redondo-Goicoechea, Alicia. «Las traducciones al francés del Amadís de Gaula en el siglo XVI y la sociología de la literatu- 
ra», in: L'internationalité littéraire, A. Pym (ed.), Paris/Barcelona, Noesis, 1988.

Rodríguez de Montalvo, Garci. Amadis de Gaule, Livre I, M. Bideaux (ed.), Paris, Classiques Garnier, 2006.

Sales Dasí, Emilio José. «Las continuaciones heterodoxas (el Florisando [1510] de Páez de Ribera y el Lisuarte de Grecia [1526] de Juan Díaz) y ortodoxas (el Lisuarte de Grecia [1514] y el Amadís de Grecia [1530] de Feliciano de Silva) del Amadís de Gaula», Edad de Oro, XXI, 2002, págs. 117-152.

Sales Dasí, Emilio José. «Una primera aproximación a la heráldica literaria de las continuaciones caballerescas del Amadís de Gaula», Emblemata. Revista Aragonesa de Emblemática, IX, 2003, págs. 219-230.

Salvo García, Irene. «Images de la construction ou la construction imaginée: les miniatures des manuscrits des Cantigas a Santa María d'Alphonse X», in: V. Obry \& C. Dauphant (eds.), in: Rêves de pierre et de bois. Imaginer la construction au Moyen Âge, Paris, PUPS, 2009, págs. 23-32.

Sáinz de la Maza Vicioso, Carlos. «Sinrazón de Montalvo/razón de Feliciano da Silva ('Amadís de Grecia')», Dicenda, 10, 1991, págs. 277-291.

SAnz Julián, María. «De la materia troyana a la caballeresca a través de los grabados: el uso de las imágenes en tres Historias Troyanas alemanas», eHumanista. Journal of Iberian Studies, 16, 2010, págs.160-183.

Serrano, Florence. La Querelle des femmes à la cour, entre la Castille et la Bourgogne, au XVé siècle: étude et édition critique du Triunfo de las donas/Triumphe des dames de Juan Rodríguez del Padrón, tesis doctoral dirigida por C. Heusch y V. Duché, ENS de Lyon, 2011.

Silva, Feliciano da, Amadís de Grecia, (eds.) A. C. Bueno Serrano \& C. Laspuertas Sarvisé, Alcalá de Henares, Centro de Estudios Cervantinos, 2004. 
Silva, Feliciano da, Amadís de Grecia. Choronica del muy valiente y esforçado principe y cuallero de la ardiente espada Amadis de Grecia, hijo de Lisuarte de Grecia, Emperador de Constantinopla y de Trapisonda, y Rey de Rodas que tracta de sus grandes hechos en Armas, $y$ de sus altos, y estraños Amores: y es el noueno libro de Amadis de Gaula, Simão Lopes, Lisboa, 1596.

Silva, Feliciano da, Amadís de Grecia. El noueno libro de Amadis de Gaula, que es la cronica del muy valiente y esforçado cauallero dela ardiente espada Amadis de grecia, hijo de Lisuarte de grecia, Emperador de Constantinopla y de Trapisonda, y Rey de Rodas que tracta de los sus grandes hechos en armas y de los sus altos y estraños amores, Jacobo Cromberger, Sevilla, 1549.

Silva, Feliciano da, Amadís de Grecia. El noueno libro de Amadis de Gaula que es la cronica del muy valiente y esforçado principe y cauallero dela ardiente espada Amadis de Grecia, hijo de Lisuarte de Grecia, Emperador de Constantinopla y de Trapisonda, y rey de Rodas que tracta de los sus altos y estraños amores, Jacobo Cromberger, Sevilla, 1542.

Silva, Feliciano da, Le huitieme livre d'Amadis de Gaule, mis en François par le Seigneur des Essars Nicolas de Herberay, Commissaire ordinaire de l'artillerie du Roy, E Lieutenant en icelle, es païs $\mathcal{E}$ grouvernement de Picardie, de Monsieur de Brissac, Chevalier de l'ordre, grand maistre \& Capitaine general d'icelle artillerie, Acuerdo Olvido, Anvers, Guillaume Sylvius, 1573.

Silva, Feliciano Da, Le septieme livre d'Amadis de Gaule, mis en François par le Seigneur des Essars Nicolas de Herberay, Commissaire ordinaire de l'artillerie du Roy, E Lieutenant en icelle, es païs \& grouvernement de Picardie, de Monsieur de Brissac, Chevalier de l'ordre, grand maistre E Capitaine general d'icelle artillerie, Acuerdo Olvido, Anvers, Guillaume Sylvius, 1573.

Silva, Feliciano da, Le huitieme livre d'Amadis de Gaule, mis en François par le Seigneur des Essars Nicolas de Herberay, Commissaire ordinaire de l'artillerie du Roy, E Lieutenant en icelle, es païs $\mathcal{E}$ grou- 
vernement de Picardie, de Monsieur de Brissac, Chevalier de l'ordre, grand maistre $\mathcal{E}$ Capitaine general d'icelle artillerie, Acuerdo Olvido, Anvers, Christophe Plantin, 1561.

Silva, Feliciano da, Le septieme livre d'Amadis de Gaule, mis en François par le Seigneur des Essars Nicolas de Herberay, Commissaire ordinaire de l'artillerie du Roy, E Lieutenant en icelle, es païs $\mathcal{E}$ grouvernement de Picardie, de Monsieur de Brissac, Chevalier de l'ordre, grand maistre \& Capitaine general d'icelle artillerie, Acuerdo Olvido, Anvers, Christophe Plantin, 1561.

Silva, Feliciano da, Le huitiesme livre d'Amadis de Gaule, auquel sont recitees les hautes prouesses et faitz merveilleux d'Amadis de Grece, surnommé le Chevalier de l'ardante Espée: Mis en Françoys par le Seigneur des Essars N. de Herberay, Commissaire ordinaire de l'artillerie $d u$ Roy, E lieutenant en icellem es païs $\mathcal{E}$ gouvernement de Picardie, de monsieur de Brissac, Chevalier de l'ordre, grand Maistre, \& Capitaine general d'icelle artillerie. Acuerdo Olvido, Paris, para Vincent Sertenas, 1550.

Silva, Feliciano Da, Le huitiesme livre d'Amadis de Gaule, auquel sont recitees les hautes prouesses et faitz merveilleux d'Amadis de Grece, surnommé le Chevalier de l'ardante Espée: Mis en Françoys par le Seigneur des Essars N. de Herberay, Commissaire ordinaire de l'artillerie du Roy, E lieutenant en icellem es païs $\mathcal{E}$ gouvernement de Picardie, de monsieur de Brissac, Chevalier de l'ordre, grand Maistre, E Capitaine general d'icelle artillerie. Acuerdo Olvido, Paris, Estienne Groulleau, 1548.

Silva, Feliciano Da, Le septiesme livre d'Amadis de Gaule, histoire tres excellente d'Amadis de Grece, surnommé le chevalier de l'ardante espée, filz de Lisuart de Grece, E de la belle Onolorie de Trebisonde: mis en François par le Seigneur des Essars Nicolas de Herberay, Commissaire ordinaire de l'artillerie du Roy, Acuerdo Olvido, Paris, Jeanne Marnef pour Vincent Sertenas.

Vaganay, Hugues (1906). Amadis en français. Essai de bibliographie et d'iconographie, Florence, Olschki, 1546. 
Vaganay, Hugues. "Les éditions in-octavo de l'Amadis en français», Revue hispanique, t. 75, nº167, págs. 1-53, 1929.

Vargas Díaz-Toledo, Aurelio. «Huellas del Amadís en Francia (las fiestas celebradas en Châtellerault, en 1541, con motivo de la boda de Jeanne d'Albret y Guillaume de la Marck)», in: Amadís de Gaula: quinientos años después. Estudios en homenaje a Juan Manuel Cacho Blecua, (eds.) J.M. Lucía Megías, Ma.C. Marín Pina, con la colaboración de A.C. Bueno, Alcalá de Henares, Centro de Estudios Cervantinos, 2008, págs. 819-834.

VALENTIN, ÉmiLE. «L' Amadis espagnol et sa traduction française: évolution stylistique et continuité thématique», Linguistica antverpensia, X, 1976, págs. 149-167.

Florence Serrano

UNIVERSITÉ DE LORRAINE 